\title{
Evaluation of the 2017/18 Influenza Epidemic Season in Poland Based on the SENTINEL Surveillance System
}

\author{
K. Łuniewska, K. Szymański, E. Hallmann-Szelińska, \\ D. Kowalczyk, R. Sałamatin, A. Masny, and L. B. Brydak
}

\begin{abstract}
The SENTINEL influenza surveillance system is an important tool for monitoring influenza in Poland. Data from this system are necessary to determine the dynamics of seasonal infections and to announce the epidemic by the country level. For the 2017/18 epidemic season, the dominance of influenza type B was recorded and the highest percentage of infections was recorded in the age group 45-64 years. Among the subtypes of influenza type A, A/H1N1/ pdm09 was the predominated subtype. Most cases were reported in the age group of 26-44 and $0-4$ years. The influenza virus frequently undergoes modifications. Therefore, it is necessary to constantly monitor the emerging strains around the world.
\end{abstract}

\section{Keywords}

Epidemic season $\cdot$ Influenza $\cdot$ Respiratory tract $\cdot$ SENTINEL system $\cdot$ Surveillance . Virology

K. Łuniewska ( $\bowtie)$, K. Szymański, E. HallmannSzelińska, D. Kowalczyk, A. Masny, and L. B. Brydak Department of Influenza Research, National Influenza Center, National Institute of Public Health- National Institute of Hygiene, Warsaw, Poland e-mail: kluniewska@pzh.gov.pl

R. Sałamatin

Department of General Biology and Parasitology, Warsaw Medical University, Warsaw, Poland

\section{Introduction}

The SENTINEL Influenza Surveillance System allows monitoring of the course and dynamics of epidemic seasons in Poland. Virological data tallied by 16 Voivodship Sanitary and Epidemiological Stations of the country allow to identify the dominant virus strain and to provide information on the age groups that are most vulnerable to the virus (Cieślak et al. 2017). Monitoring of the influenza virus activity in the inter-pandemic period also is a part of the national surveillance plan in Poland. The information about the emergence of a new pandemic strain can be obtained immediately, and thus the anti-influenza measures implemented at the national level (Bednarska et al. 2016).

In 2009, the EU Commission has issued recommendations in which it is assumed that the influenza vaccination rate in high-risk groups should reach $75 \%$ in all European countries up to the 2014/15 epidemic season. The risks groups included adults above 65 years of age and all persons over 6 months of age with chronic diseases (ECDC 2017). However, this goal has not been achieved in most of the countries (Weimbergen 2018). The vaccination rate in the 2017/18 epidemic season in the population of Poland amounted to $3.4 \%$. Such a dismal vaccination rate places the country in the last place in Europe (Brydak 2019). Further, seasonal 
epidemics occur in Poland every year, causing a large number of deaths and post-influenza morbidity, incurring huge socioeconomic costs (Brydak 2018). The epidemics cannot be properly countered without a proper population vaccination rate, the main preventive measure against influenza. This study seeks to define the dynamics of influenza infections and the prevalence of dominant viral types in Poland during the 2017/ 18 epidemic season, based on the data tallied by the SENTINEL influenza surveillance program.

\section{$2 \quad$ Methods}

The study material included nasal and pharyngeal swab samples analyzed in 16 Voivodship Sanitary and Epidemiological Stations and in the Department of Influenza Research, National Influenza Center in National Institute of Public Health - National Institute of Hygiene. Data were analyzed and reported using the SENTINEL Influenza Surveillance System. A total of 1,585 patients participated in the study. They were divided into 7 age groups: $0-4,5-9,10-14$, 15-25, 26-44, 45-64, and 65+ years.

Specimens collected from patients were analyzed for the identification of influenza type $\mathrm{A}$ and $\mathrm{B}$ viruses by PCR techniques. From a $200 \mu \mathrm{l}$ clinical sample suspended in physiological saline, $50 \mu \mathrm{l}$ of viral RNA resuspended in RNasefree water was obtained. For the assay, a Maxwell 16 Viral Total Nucleic Acid Purification Kit was used (Promega Corporation; Madison, WI) according to the manufacturer's instructions. The analytes were further analyzed to determine viral subtypes using a Light Thermocycler 2.0 System (Roche Diagnostics; Rotkreuz, Switzerland). The primers and probes were obtained from the International Reagent Resource run by the Centers for Disease Control and Prevention (CDC). The reaction was carried out in accordance with the manufacturer's instructions. To obtain cDNA, RNA was subjected to reverse transcription (at $50{ }^{\circ} \mathrm{C}$ for $30 \mathrm{~min}$ ). Then, cDNA was subjected to the initiating process ( 1 cycle of $95{ }^{\circ} \mathrm{C}$ for $2 \mathrm{~min}$ ) followed by 45 cycles of amplification: denaturation at $95{ }^{\circ} \mathrm{C}$ for $15 \mathrm{~s}$, annealing at $55{ }^{\circ} \mathrm{C}$ for $10 \mathrm{~s}$, and elongation at $72{ }^{\circ} \mathrm{C}$ for $20 \mathrm{~s}$. Positive control constituted viral RNA obtained from the vaccine strains for the current epidemic season (A/Michigan/45/2015 (H1N1)pdm09,

A/HongKong/4801/2014 (H3N2), B/Brisbane/60/2008), and negative control constituted RNase-free water.

Using the reverse transcription polymerase chain reaction, the presence of 15 respiratory viruses was confirmed in the samples. The viruses consisted of Influenza A virus, Influenza B virus, Human respiratory syncytial virus $\mathrm{A}$ and $\mathrm{B}$, Human adenovirus, Human metapneumovirus, Human coronavirus 229E/NL63, Human coronavirus OC43, Human parainfluenza 1, 2, 3, and 4, Human rhinovirus A/B/C, Human enterovirus, and Human bocavirus $1 / 2 / 3 / 4$. For the assay, RV15 OneStep ACE Detection Kit (Seeplex; Seoul, South Korea) was used according to the manufacturer's instructions. When the reaction was completed, the product was separated on a $2 \%$ agarose gel by electrophoresis.

The probability of occurrence of influenza infection was estimated using a logistic regression model. Odds ratios were calculated for all age groups with reference to the $65+$ group. The statistical analysis was performed using commercial IBM SPSS statistical software (Armonk, NY).

\section{Results}

In the 2017/2018 epidemic season, a total of 1,585 samples, one from each individual, were collected through the SENTINEL Influenza Surveillance System. The overall number of analyzed samples remained at a low level until Week 1 of 2018, not exceeding 24 per week. Later on, there was a rapid increase in the number of tested samples, which peaked in Week 8 reaching 196 samples, except for Week 7 when this number retreat to 128 samples. The situation was different when we analyzed the number of positive samples in a given week. The first positive samples were recorded at Week 48 of 2017 ( $15.8 \%$ of weekly samples). A steady increase in 
influenza cases was reported from Week 1 of 2018 (23.5\% positive), exceeding $47.0 \%$ of the samples tested in Week 11. The highest percentage of positive samples was recorded at Week 10 of 2018 , which amounted to $65.6 \%$. There was a decrease in the percentage of positive findings in the following weeks until Week 16, when there was a drop to zero noted (Fig. 1).

Comparing the recent epidemic seasons starting from 2014/15 up to 2017/18, an increase in the number of confirmed cases of influenza from 221 to 708 cases, respectively, is observed. An increase also is observed in the percentage terms, from $33.8 \%$ to $44.7 \%$, respectively, although this increase has plateaued in the last season as the greatest, amounting to $46.6 \%$, was observed in before last 2016/17 epidemic season (Table 1).
In then $2017 / 18$ epidemic season, a total of 708 influenza infections and 28 influenza-like viral infections were confirmed. Of the 708 influenza infections, 204 were due to influenza A virus and 504 due to influenza B virus. Influenza A infections were dominated by the subtype A/H1N1/pdm09 (38 cases). Influenza-like infections viruses were dominated by respiratory syncytial virus (16 cases).

The findings of this study were reanalyzed in 7 successive age groups. The highest percentage of influenza B infections was found in the age group of 45-64 (21.6\%) years, while that of influenza $A$ in the group of 26-44 (7.6\%) years. The dominance of influenza A over B was found only in the youngest age group of $0-4$ years. There was a distinct dominance of influenza $B$ virus in the remaining age groups (Fig. 2).

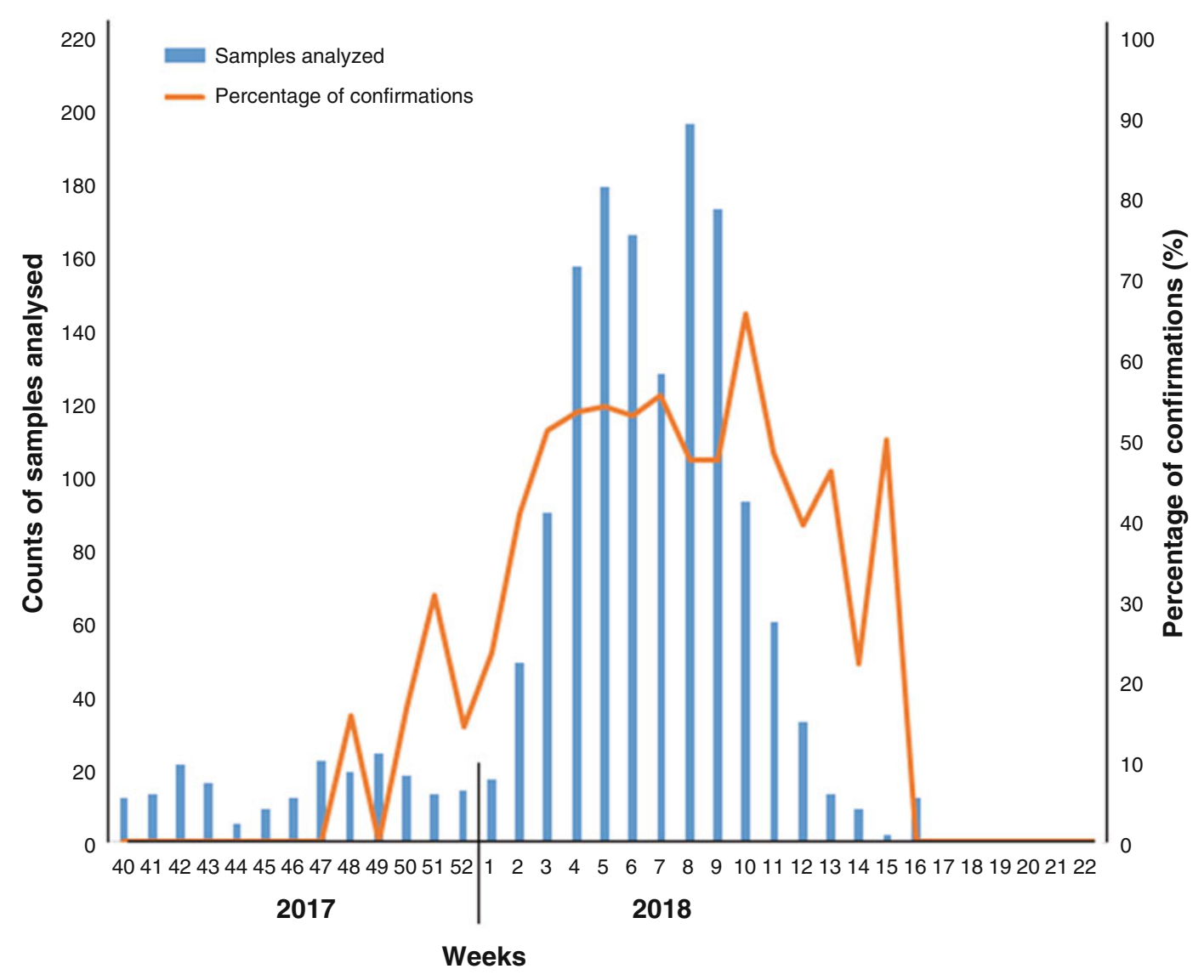

Fig. 1 Dynamics of the 2017/18 influenza epidemic season based on the SENTINEL surveillance system in Poland 
Table 1 Influenza infections in recent epidemic seasons

\begin{tabular}{l|l|l|c|r}
\hline Epidemic season & $2014 / 15$ & $2015 / 16$ & $2016 / 17$ & $2017 / 18$ \\
\hline Number of samples analyzed & 653 & 1,625 & 1,283 & 1,585 \\
\hline Number of confirmed cases & 221 & 603 & 598 & 708 \\
\hline Percentage of confirmations & $33.8 \%$ & $37.1 \%$ & $46.6 \%$ & $44.7 \%$ \\
\hline
\end{tabular}

Fig. 2 Percentage of confirmed influenza infections in the $2017 / 18$ epidemic season in successive age groups of patients

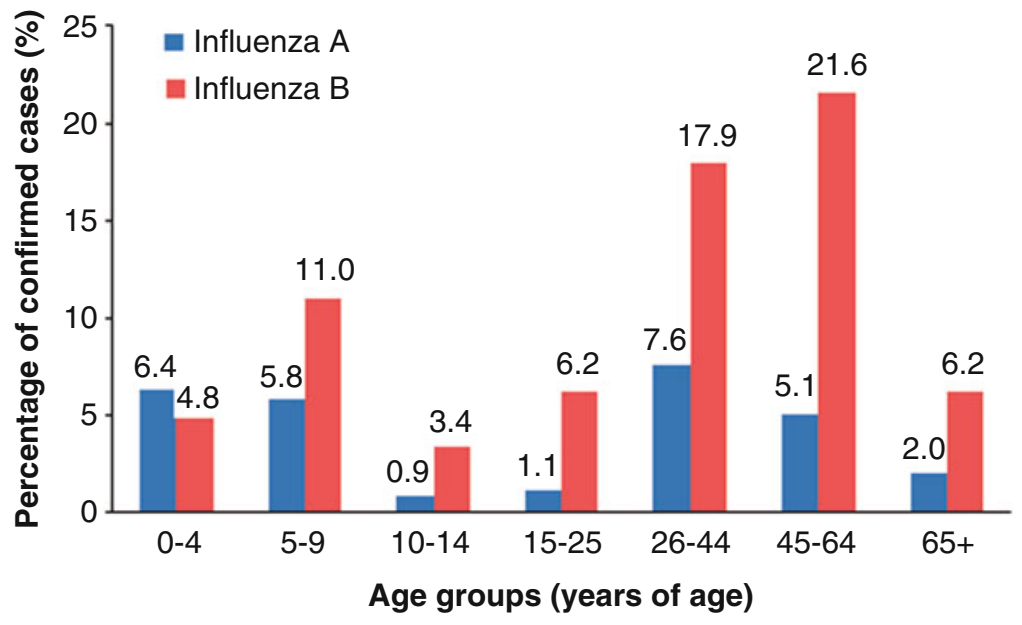

\section{Discussion}

The SENTINEL Influenza Surveillance System is an essential tool for monitoring influenza in Poland. Data from this system are key to determine the dynamics of season infections and to announce the epidemic by the relevant authorities in the country (Cieślak et al. 2018; Lee et al. 2018). Comparing the increasing number of confirmed cases of influenza in the 2017/18 epidemic season in Poland with other European countries, we notice almost the same situation. In Germany, single positive samples have been recorded since the season's beginning, i.e., Week 40 of 2017. The highest number of cases and the highest percentage of positive samples (over 60\%) were recorded there in Week 9, which closely corresponds to the Polish data. In Czech Republic, the threshold of over $60 \%$ of positive specimens was achieved 
already in Week 5 and lasted until Week 9. Further, the dominance of influenza type $\mathrm{B}$ has been reported there, similarly to the epidemiological situation in Poland. Concerning influenza type A, subtype A/H1N1/pdm09 has also dominated (FluNews Europe 2018). This trend has been different from that in the 2016/17 season, when the subtype $\mathrm{A} / \mathrm{H} 3 \mathrm{~N} 2 /$ dominated, while the $\mathrm{A} / \mathrm{H} 1 \mathrm{~N} 1 /$ pdm09 was not recorded (Cieślak et al. 2018). The first positive specimens in Poland were recorded in Week 48, which distinguishes the current season from the previous one. The 2016/17 season started earlier, because the threshold of $10 \%$ of positive tests has already been exceeded from Week 46 onward (Adlhoch et al. 2018).

In the 2017/18 epidemic season, the dominance of subtype A/H1N1/pdm09 among the influenza A subtypes was noticed. Most cases were reported among the patients of 26-44 and 0-4 years of age. A similar situation took place in the course of the 2009 pandemic when the subtype A/H1N1/pdm09 had infected mainly children and young adults, while it was responsible for just $10 \%$ of hospitalization of the elderly (Verma et al. 2012). In the previous 2016/17 influenza season, $\mathrm{A} / \mathrm{H} 3 \mathrm{~N} 2 /$ dominated in terms of the percentage of influenza cases; a subtype that is known for its propensity to infect the elderly (Pebody et al. 2017).

Over the last four influenza epidemic seasons, we have observed an increase in the percentage of confirmed influenza infections reported in the SENTINEL Surveillance System. That shows a steady improvement in the surveillance system and in the knowledge and ability to recognize and verify the infection and its type. In the last two influenza seasons of 2016/17 and 2017/18, the percentage of confirmed cases ranged around $45 \%$, which means that almost every second patient was properly diagnosed by general practitioners.

The present report demonstrates the dynamics of the 2017/18 influenza season in Poland according to the data from Sentinel Surveillance System. The virological data are valuable in that they serve to accurately determine the antigenic composition of vaccine for the next epidemic season.
Acknowledgments We thank physicians and employees of VSES who participated in the SENTINEL program for their input in the influenza surveillance in Poland. Supported by NIPH-NIH theme 3/EM.

Conflicts of Interest The authors declare no conflicts of interests in relation to this article.

Ethical Approval All procedures performed in studies involving human participants were in accordance with the ethical standards of the institutional and/or national research committee and with the 1964 Helsinki declaration and its later amendments or comparable ethical standards. The study was approved by the Ethics Committee of the NIPH-NIH in Warsaw, Poland.

Informed Consent Informed consent for taking nasopharyngeal swab specimens was obtained from all patients included in the study or their legal quardians at the time of sampling.

\section{References}

Adlhoch C, Snacken R, Melidou A, Ionescu S, Penttinen $P$, The European Influenza Surveillance Network (2018) Dominant influenza A(H3N2) and B/Yamagata virus circulation in EU/EEA, 2016/17 and 2017/18 seasons, respectively. Eur Secur 23 (13): 18-00146

Bednarska K, Hallmann-Szelińska E, Kondratiuk K, Brydak LB (2016) Influenza surveillance. Postepy Hig Med Dosw 70:313-318

Brydak LB (2018) Health and economic impacts of influenza infections in the context of public health in Poland. In: Nowakowska E (ed) Pharmacoeconomics in the management of health care resources. Wolters Kluwer Poland. (Article in Polish)

Brydak LB (2019) Flu - prevention and treatment in children and adolescents. Pediatr Med Stand 2:16

Cieślak K, Kowalczyk D, Szymański K, Brydak LB (2017) The Sentinel system as the main influenza surveillance tool. Adv Exp Med Biol 980:37-43

Cieślak K, Szymański K, Kowalczyk D, HallmannSzelińska E, Brydak LB (2018) Virological situation in Poland in the 2016/2017 epidemic season based on Sentinel data. Adv Exp Med Biol 1108:63-67

ECDC (2017) European centre for disease prevention and control. Seasonal influenza vaccination in Europe. Vaccination recommendations and coverage rates in the EU member states for eight influenza seasons: 2007-2008 to 2014-2015. https://ecdc.europa.eu/ sites/portal/files/documents/influenzavaccination2007\%E2\%80\%932008-to-2014\%E2\%80\%932015. pdf. Accessed on 26 June 2018

FluNews Europe (2018). https://flunewseurope.org/. Accessed on 26 June 2019 
Lee EC, Arab A, Goldlust SM, Viboud C, Grenfell BT, Bansal S (2018) Deploying digital health data to optimize influenza surveillance at national and local scales. PLoS Comput Biol 14(3): 1006020

Pebody R, Warburton F, Ellis J, Andrews N, Potts A, Cottrell S, Reynolds A, Gunson R, Thompson C, Galiano $M$, Robertson C, Gallagher N, Sinnathamby M, Yonova I, Correa A, Moore C, Sartaj M, de Lusignan S, McMenamin J, Zambon M (2017) End-of-season influenza vaccine effectiveness in adults and children, United Kingdom, 2016/17. Eur Secur 22(44):17-00306

Verma N, Dimitrova M, Carter DM, Crevar CJ, Ross TM, Golding H, Khurana S (2012) Influenza virus H1N1pdm09 infections in the young and old: evidence of greater antibody diversity and affinity for the hemagglutinin globular head domain (HA1 domain) in the elderly than in young adults and children. J Virol 86 (10):5515-5522

Weimbergen B (2018) Vaccines for elderly: current use and future challenges. Immun Ageing 15:3 